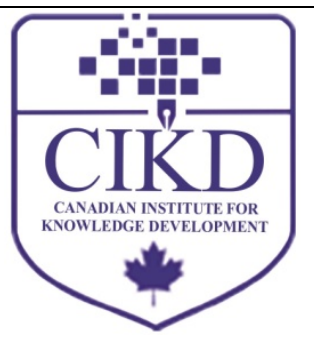

\title{
Leadership and Organization for the Companies in the Process of Industry 4.0 Transformation
}

\author{
Özlem Akçay Kasapoğlu \\ Istanbul University Faculty of Business, Operations Management Department
}

\section{Keywords: \\ Leadership, Disruptive \\ Technology, Industry 4.0, Analytical Hierarchy \\ Process, Quality Function \\ Deployment, Smart \\ Factories}

\section{Received}

16 May 2018

Received in revised form

22 August 2018

Accepted

25 August 2018

Correspondence:

ozlemak@istanbul.edu.tr

\begin{abstract}
The global effect of disruptive technology has brought about huge productivity improvements in manufacturing. The changing and differentiated demand of the customers pushed the industry to improve their production systems in the Industry 4.0 concept for being more responsive to the changing conditions. The increased knowledge level on the data science made the data analytics possible and more meaningful. Industry 4.0 is the common name used to describe the current trend towards a fully connected and automated manufacturing system, or Smart Factory. All production decisions are optimized based on real time information from a fully integrated and linked set of equipment and people. There is an urgency in the manufacturing companies to change their technology, knowledge, and he workforce skills for the Industry 4.0 understanding in order to stay competitive. The transformation process to the Industry 4.0 concept is a strategic decision and it requires leadership to deploy the strategy all through the organization by training from the top to the bottom of the organization.
\end{abstract}

CAIMI Journals

New achievements in information and communication technologies (ICT) are drastically influencing several industrial sectors. The provision of connectivity, networked entities, realtime data, and pervasive information is shifting paradigms in industries. However, this rapid evolution requires a proper comprehension and definition by scholars and practitioners in order to achieve a broad dissemination of the technological progress. Today, the trend towards a digital revolution in manufacturing is known as "Industry 4.0". However, the footprint of these 
evolutions, the technological borders, and the application frameworks are not yet specified. Therefore, the adoption of this paradigm change still requires more research to further develop the knowledge about the drivers and accomplishments of Industry 4.0. (Santos, Mehrsai, Barros, Araújo, \& Ares, 2017).

The vision of Industry 4.0 emphasizes the global networks of machines in a smart factory setting capable of autonomously exchanging information and controlling each other. This cyber-physical system allows the smart factory to operate autonomously. For instance, a machine will know the manufacturing process that needs to be applied to a product, what variation to be made to that product so that the product can be uniquely identifiable as an active entity whose configuration and route in the production line is unique. As collaboration between suppliers, manufacturers and customers is crucial to increase the transparency of all the steps from when the order is dispatched until the end of the life cycle of the product, it is therefore necessary to analyze the impact of Industry 4.0 on the supply chain as a whole. (Tjahjono, Esplugues, Ares, \& Pelaez, 2017).

The contribution of the leaders make to the performance of their organizations can be significant. Upper echelons theory urges that decisions and choices of top management have an influence on the performance of the organization positive or negative through their assessment of the environment, strategic decision making and support for innovation. The results of the different studies vary, but the reviews of research on leadership and performance suggest leadership directly influences around \% 15 of the differences found in the performance of the businesses and contribute around an additional 35\% through the choice of business strategy. Thus, directly or indirectly leadership can account for half of the variance in performance observed across the organizations (Tidd \& Bessant, 2014, p. 62).

Despite all efforts, many product development projects fail and lead to the introduction of products that do not meet customers' expectations. A high level of customer satisfaction cannot be obtained. On the other hand, in many product development projects, the process of product development is conducted very unsystematically and resources are wasted because of a lack of communication between the different functions involved in product development. Time especially is a critical factor within product development as time to market is becoming increasingly more important. Managers need a set of practical step-by-step tools and methods which ensure a better understanding of customers' needs and requirements as well as procedures and processes to enhance communication by focusing on the voice of the customer within a product development project (Matzlera \& Hinterhuberb, 1998).

Recent advances in manufacturing industry has paved the way for a systematical deployment of Cyber-Physical Systems (CPS), within which information from all related perspectives is closely monitored and synchronized between the physical factory floor and the cyber computational space. Moreover, by utilizing advanced information analytics, networked machines will be able to perform more efficiently, collaboratively and resiliently. Such trend is transforming manufacturing industry to the next generation, namely Industry 4.0. (Lee, Bagheri, \& Kao, 2015).

Falle and Feldmüller (2015) mentioned in their study that the regional SMEs need further training in modern technologies enabling Industry 4.0 scenarios and methods to optimize their production themselves. This is delivered by the learning factory with 3 different training 
setups. Besides this, it is used for the practical teaching of the students and for evaluating research projects.

Rennung, Luminosu, and Draghici (2016) emphasized the progress of the "Industry 4.0" in an increasing number of cases. Project is unsatisfactory and takes on a crisis-like character. Previous research in the context of the concept "Industry 4.0" focuses on production environments. By conducting expert interviews, the relevance of services for the future project is examined.

The manufacturing industries are currently changing from mass production to customized production. The rapid advancements in manufacturing technologies and applications in the industries help in increasing productivity. The term Industry 4.0 stands for the fourth industrial revolution which is defined as a new level of organization and control over the entire value chain of the life cycle of products; it is geared towards increasingly individualized customer requirements. Industry 4.0 is still visionary but a realistic concept which includes Internet of Things, Industrial Internet, Smart Manufacturing and Cloud based Manufacturing. Industry 4.0 concerns the strict integration of human in the manufacturing process so as to have continuous improvement and focus on value adding activities and avoiding wastes (Vaidya, Ambad, \& Bhosle, 2018).

In today's world, the supply chains must be responsive to be able to survive. Responsiveness is the ability to respond to wide ranges of quantities demanded, meet short lead times, handle a large variety of products, build highly innovative products, and meet a very high service level. Responsiveness comes at a cost. Supply chain efficiency is the inverse to the cost of making and delivering the product to the customer. In recent years, there has been appreciable activity in manufacturing value creation resulting in that the ability to create value is based on the competence to make decisions and implement strategies for Industry 4.0 (Velinov, Maly, \& Vojvodic, 2018).

In this global world understanding the customers is a must. Pull strategy all through the supply chain must be applied and data should be shared among the upstream. Agile and responsive strategy can only be applied only if the customers are listened. In today's industry, where the growing distance between producers and users is a concern, Quality Function deployment method links the needs of the customer with design, development, and manufacturing with the Industry 4 concept. This is the only way to survive in this highly competitive world. Digitalization or so called Industry 4.0 will help the companies to have more responsive operations and supply chains. The determination of the transformation requires a strategic plan and a good organization till the end of the life cycle.

Organization design enables creativity, learning and interaction, shared vision, leadership and the will to innovate, appropriate structure, key individuals, effective team working, high involvement innovation, creative climate, external focus and clearly articulated and shared sense of purpose stretching strategic intent (Tidd \& Bessant, 2014, p. 62). The deployment of this strategy requires the organization of the right trainings. The aim is to increase the understanding of Industry 4.0 all through the organization and to stay responsive and competitive and it can only be done by understanding the customer. 


\section{Method}

The study was done in four phases:

1. The understanding of the manufacturing firms on Industry 4.0 transformation was measured by the analytical hierarchy process technique. The three groups assigned importance weights to the criteria under industry 4.0.

2. The trainings were performed to the 30 people who had masters and $\mathrm{PhDs}$ and they were called academics, to 30 engineers who were called white colored workers and 30 students who were apprentices in the manufacturing company. Later on the three groups' scores on the training were analyzed to find if there was significance in their learning.

3. In the third phase the effectiveness of the training was measured to see if there was a significant difference between before and after the training in the white color workers.

4. The white color workers, who had a good learning from the training, applied Quality Function Deployment (QFD) technique to the customers to bring this customer interface to modern manufacturing and business. Where the growing distance between producers and users is a concern, QFD links the needs of the customer with design, development, and manufacturing with the Industry 4 concept.

When multiple objectives are important to a decision maker, it is often difficult to choose between alternatives. Thomas Saaty's Analytic Hierarchy Process (AHP) provides a powerful tool that can be used to make decisions in situations where multiple objectives are present. AHP has been used by decision makers in many areas including accounting, finance, marketing, energy resource planning, sociology and political science (Winston \& Albright, 2011).

The AHP is a theory of relative measurement on absolute scales of both tangible and intangible criteria based both on the judgment of knowledgeable and expert people and on existing measurements and statistics needed to make a decision. The four main steps of the AHP can be summarized as follows (Tzeng \& Huang, 2011):

Step 1: Set up the hierarchical system by decomposing the problem into a hierarchy of interrelated elements;

Step 2: Compare the comparative weight between the attributes of the decision elements to form the reciprocal matrix;

Step 3: Synthesize the individual subjective judgment and estimate the relative weight;

Step 4: Aggregate the relative weights of the elements to determine the best alternatives/strategies.

The first step in AHP is to create a pairwise comparison matrix for each alternative on each criterion. The values shown in Table 3 are used in AHP to describe the decision maker's preferences between two alternatives on a given criterion.

\section{Application}

Phase 1: The understanding of the manufacturing firms on Industry 4.0 transformation was measured by the analytical hierarchy process technique. Figure 1 shows the hierarchy view of the criteria and sub criteria that are prepared based on the Turkish roadmap for the Industry 
4.0 from Tubitak. The three groups were assigned importance weights to the criteria under industry 4.0 .

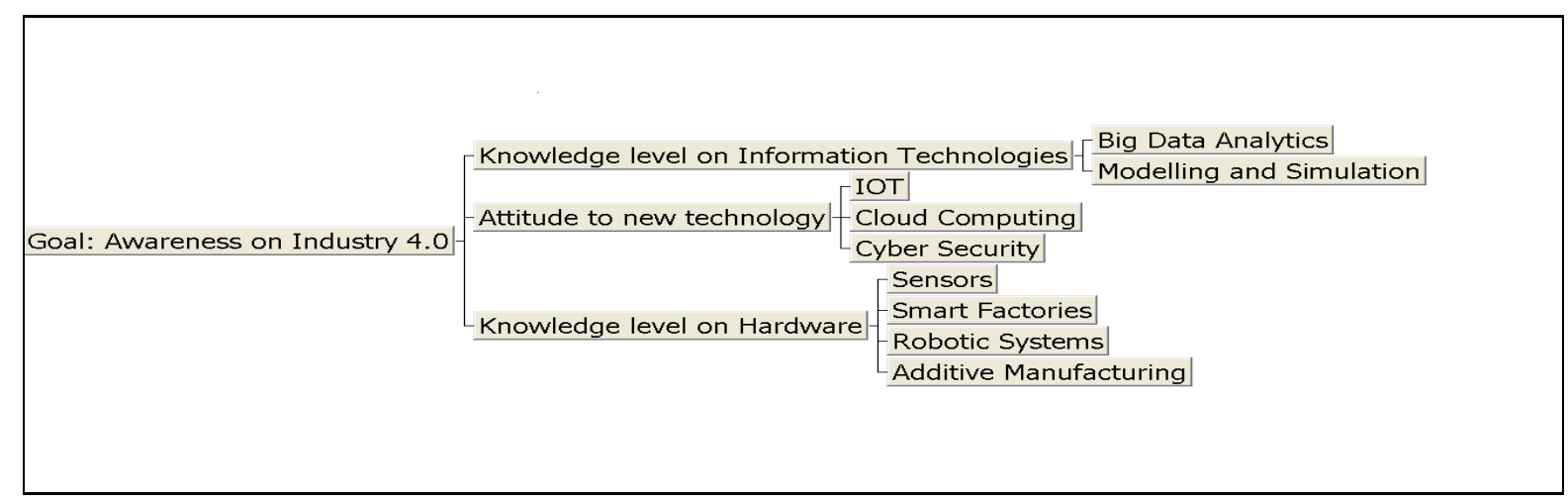

Figure 1. Hierarchy view of the criteria on awareness on Industry 4.0

Pairwaise comparisons for the main criteria which are given in the hierarchical view of AHP were calculated. Academic personnel overall priorities for the main 3 criteria "Knowledge level on the information technologies" is .635, "Attitude to the new technologies" is .287, "Knowledge level on hard ware" is .78. Industry white color workers "overall priorities for the main criteria "Knowledge level on the information technologies" is .487, "Attitude to the new technologies" is .078, "Knowledge level on hard ware" is .435. Students' overall priorities for the main criteria "Knowledge level on the information technologies" is .131, "Attitude to the new technologies" is .561, "Knowledge level on hard ware" is .208. The Industry white color workers' overall priorities on awareness for the Industry 4.0 with analytical hierarchy process are presented in Figure 2.

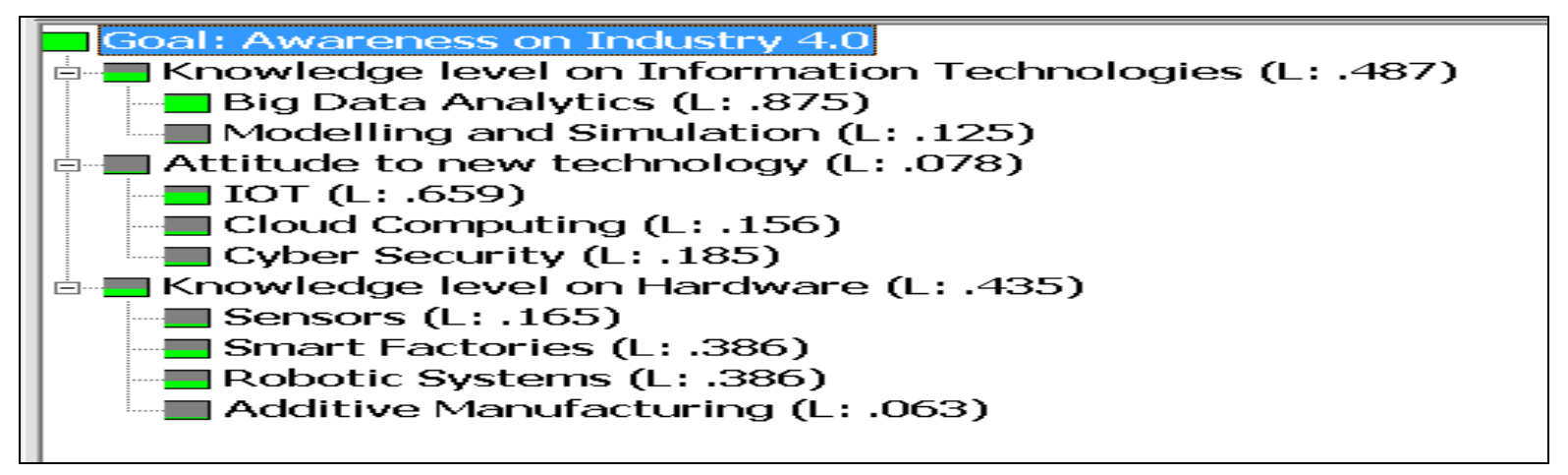

Figure 2. Industry white color workers' overall priorities on awareness for the Industry 4.0 with analytical hierarchy process

Phase 2: The statistical analysis for the comparison of three groups for learning.

The training is applied to the three groups and their learning levels were tested.

\section{Hypothesis for the Test of the Homogeneity of Variances}

$\mathrm{H}_{0}$ :There is homogenity of variances between groups

$\mathrm{H}_{1}$ :There is no homogenity of variances between groups 
Table 1

Test of Homogenity of Variances

Levene Statistic

8.79

df1

df2

.001

\section{The Comparison of Three Groups for Learning}

$\mathrm{H}_{0}$ : There is no significant difference between the learning level of the three groups

$\mathrm{H}_{1}$ : There is a significant difference between the learning level at least at one of the three groups

As shown in Table 2, we reject the null hypothesis. There is a significant difference between the learning level at least at one of the three groups.

Table 2

One Way ANOVA

\begin{tabular}{lccccc}
\hline & Sum of Squares & df & M & F & p \\
\hline Between Groups & 3246.66 & 2 & 1623.33 & 7.62 & .001 \\
Within Groups & 18513.33 & 87 & 212.79 & & \\
Total & 21760.00 & 89 & & & \\
\hline
\end{tabular}

Posthoc tests were conducted to see the difference among the groups. As presented in Table 1 , we reject the null hypothesis because the significance values are smaller than the p-value of .005. We conclude that there is no homogeneity of variances between groups; therefore, the Tamhane Test is selected under The Post Hoc tests, as presented in Table 3.

Table 3

Multiple Comparisons

\begin{tabular}{|c|c|c|c|c|c|c|c|}
\hline & \multirow{2}{*}{ (I) kategoric } & \multirow{2}{*}{ (J) kategoric } & \multirow{2}{*}{ Mean Difference (I-J) } & \multirow{2}{*}{ Std. Error } & \multirow{2}{*}{ Sig. } & \multicolumn{2}{|c|}{$95 \%$ Confidence Interval } \\
\hline & & & & & & Lower Bound & Upper Bound \\
\hline \multirow{3}{*}{ Tamhane } & \multirow{2}{*}{ Sector } & Students & 8.33 & 4.41 & .18 & -2.54 & 19.21 \\
\hline & & Academics & -6.33 & 3.04 & .12 & -13.91 & 1.25 \\
\hline & Students & Academics & $-14.66^{*}$ & 3.70 & .001 & -23.94 & -5.40 \\
\hline
\end{tabular}

The mean difference is significant at the 0.05 level. Dependent Variable is notes after training

In Table 4, means for groups in homogeneous subsets are displayed. It used Harmonic mean Sample Size of 30.00. The students and industry sector are in one group; their learning level is smilar but academics learning level is higher. The score of all groups is higher than 70; thus, their learning is good. The white color workers learning effectiveness is in the middle while students and are the lowest but stil higher than 70 as a score. The traning is more effective on the personel who had masters and PhDs and the engineers than the trainee students. 
Table 4

Homogeneous Subsets

\begin{tabular}{llcc} 
& & \multicolumn{2}{c}{ Subset for alpha $=0.05$} \\
\cline { 3 - 4 } & & 1 & 2 \\
\hline Students & 30 & 73.00 & 81.33 \\
Sector & 30 & 81.33 & 87.67 \\
Academics & 30 & & .249 \\
Sig. & & .092 & .249 \\
\hline
\end{tabular}

Phase 3: In the third phase, the diferences before and after the traininig were tested in the enginers' group coded as white color workers.

Hypothesis:

$\mathrm{H}_{0}$ : There is no significant diference in the scores of the group after the training.

$\mathrm{H}_{1}$ : There is a significant diference in the scores of the group after the training.

As shown in Table 5, the mean values of the scores are higher; training was performed to the 30 people from the enginers group coded as white color workers. Before training, the mean value was 59.67, while it was 81.33 after training.

Table 5

Paired Samples Statistics

\begin{tabular}{llcccc}
\hline & & $N$ & $M$ & $S D$ & Std. Error Mean \\
\hline \multirow{2}{*}{ Pair 1 } & BT & 30 & 59.67 & 16.07 & 2.93 \\
& AT & 30 & 81.33 & 15.02 & 2.74 \\
\hline
\end{tabular}

Table 6

Paired Samples Test

\begin{tabular}{|c|c|c|c|c|c|c|c|}
\hline & & M & SD & Std. Error Mean & $\mathrm{t}$ & $\mathrm{df}$ & $\mathrm{p}$ \\
\hline Pair 1 & $\mathrm{BT}-\mathrm{AT}$ & -21.66 & 23.93 & 4.37 & -4.95 & 29 & .000 \\
\hline
\end{tabular}

As shown in Table 5 and 6, the significance value is smaller than .05 ; therefore, the $\mathrm{H}_{0}$ hypotesis is rejected. It is concluded that there is a significant difference before and after training. The engineers group coded as white color workers learned from the training and they were found sufficient enough to make the quality function deployment analysis.

Phase 4: Quality Function Deployment

As displayed in Figure 3, the prioreties to the criteria found from the AHP technique of the white color workers as engineers are embeded to the quality function deployment technique to match the customer preferences with the industry for 4.0 requirements. In the first coulumn, one can see the customer needs in todays world, they want more responsive and agile systems. This coulumn is called critical customer requirements (CCRs). (What's) are listed vertically in the first column and all are related. CTQs (How's) are listed horizontally across the top. 


\section{The Findings}

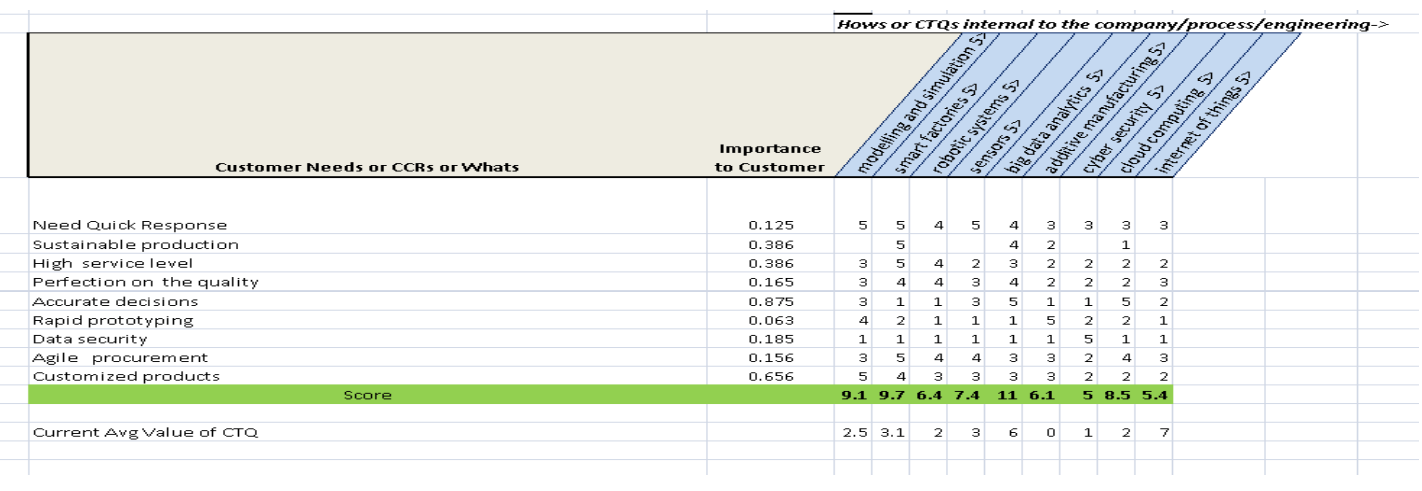

Figure 3. The quality function deployment

\section{Discussion and Conclusion}

AHP technique applied to the industrial sector. The academic people and students and the importance weights of the topics under industry 4 concept were determined. According to the impotance values, the training materials were organized by management and the success of the groups were compared. Before and after the training analysis was cunducted to the engineers and it is found that the training is effective on them. Those trainings were performed only under the leadership of the managers for the digitalization inititation.

In the QFD technique, the customers' quick response, sustainable production, high service level, perfection on quality, accurate decisions, rapid prototyping, data security, agile procurement and customized products requirements were matched with the company's capabilities under the industry 4.0 skills. In the analysis, it was found that the company should focus on smart factory concept with the 9.7 score and then modelling and simulation with 9.1 should be conducted. This would help the company for the responsivenes, customization and quality requested from the customers.

All production decisions are optimized based on real time information from a fully integrated and linked set of equipment and people. There is an urgency in the manufacturing companies to change their technology and knowledge and the workforce skills for the Industry 4.0 understanding in order to stay competitive. The transformation process to the Industry 4.0 concept is a strategic decision and it requires leadership to deploy the strategy all through the organization by training from the top to the bottom of the organization.

Agile and reponsive strategy can only be applied if the customers are listened. In today's industry, where the growing distance between producers and users is a concern, Quality Function deployment method links the needs of the customer with design, development, and manufacturing with the Industry 4 concept. This is the only way to survive in this highly competitive world. Digitalization or so called Industry 4.0 will help the companies to have more responsive operations and supply chains. 


\section{References}

Faller, C., \& Feldmüller, D. (2015). Industry 4.0 learning factory for regional SMEs. Procedia CIRP, 32, 88-91.

Lee J., Bagheri, B., \& Kao, H. (2015). Cyber-physical systems architecture for Industry 4.0-based manufacturing systems. Manufacturing Letters, 3, 18-23.

Matzlera, K., \& Hinterhuberb, H. (1998). How to make product development projects more successful by integrating Kano's model of customer satisfaction into quality function deployment. Technovation, 18(1), 25-38.

Rennung F., Luminosu, C. T., Draghici, A. (2016). Service provision in the framework of Industry 4.0. Procedia - Social and Behavioral Sciences, 221, 372-377.

Santos, C., Mehrsai, A., Barros, A. C., Araújo, M., \& Ares, E. (2017). Towards Industry 4.0: An overview of European strategic roadmaps. Procedia Manufacturing, 13, 972-979.

Tidd, J., \& Bessant, J. (2014). Strategic innovation management. United Kingdom: Willey.

Tjahjono, B., Esplugues, C., Ares, E., \& Pelaez, G. (2017). What does Industry 4.0 mean to supply chain? Procedia Manufacturing, 13, 1175-1182.

Tzeng, G. H., \& Huang, J. J. (2011). Multiple attribute decision making: Methods and applications. United State: Chapman and Hall/CRC Press.

Vaidya, S., Ambad, P., \& Bhosle, S. (2018). Industry 4.0- A glimpse. Procedia Manufacturing, 20, 233-238.

Velinov, E., Maly, M., \& Vojvodic, M. (2018). Digitalization on Boards: Evidence from the Baltic Public Listed Companies, Management and Business Research Quarterly, 6; 10-15.

Winston, W. L., \& Albright, C. (2011). Practical Management Science. United State: South-Western College. 